\title{
ПРЕЦИЗИОННАЯ МЕДИЦИНА В ОНКОЛОГИИ: МИФ ИЛИ РЕАЛЬНОСТЬ?
}

\author{
Т. А. Славянская $1,2 凶$, С. В. Сальникова ${ }^{1,2}$ \\ ${ }^{1}$ Российский университет дружбы народов, Москва, Россия
}

2 Институт иммунофизиологии, Москва, Россия

\begin{abstract}
Бурный рост числа онкологических заболеваний во всем мире диктует необходимость разработки новых, инновационных и персонализированных подходов к их лечению. Отсутствие клинических проявлений на ранних стадиях болезни не позволяет своевременно назначить адекватную терапию. Традиционные методы лечения, не всегда обладающие удовлетворительной эффективностью, не предотвращают рецидивирование, не обеспечивают достаточную ремиссию и продолжительность жизни больного. Значительные трудности представляет собой лечение инвазивного, метастатического рака. В статье представлен краткий обзор иммунологических механизмов развития злокачественных новообразований, современных традиционных и инновационных методов лечения рака, а также анализ литературных данных по использованию методов таргетной, генной терапии, специфической иммунотерапии и других подходов, лежащих в основе прецизионной медицины в онкологии.
\end{abstract}

Ключевые слова: рак, неспецифическая иммунотерапия, цитокинотерапия, таргетная терапия, моноклональные антитела, иммунные чек-поинты, противоопухолевые вакцины, генная терапия, нанотехнологии, прецизионная медицина

Информация о вкладе авторов: Т. А. Славянская - идея и план написания обзора, сбор и анализ литературы, интерпретация данных, рецензирование статьи, подбор рисунков, написание выводов; С. В. Сальникова - сбор и анализ литературы, подготовка черновика рукописи.

$\bowtie$ Для корреспонденции: Татьяна Александровна Славянская

ул. Миклухо-Маклая, д. 6, г. Москва, 117198; tslavyanskaya@gmail.com

Статья получена: 24.08.2018 Статья принята к печати: 25.03.2019 Опубликована онлайн: 31.03.2019

DOI: $10.24075 /$ vrgmu.2019.018

\section{PRECISION ONCOLOGY: MYTH OR REALITY?}

\author{
Slavyanskaya $\mathrm{TA}^{1,2} \otimes$, Salnikova SV ${ }^{1,2}$ \\ ${ }^{1}$ Peoples' Friendship University of Russia, Moscow, Russia \\ 2 Institute of Immunophysiology, Moscow, Russia
}

Cancer incidence rates are growing at an alarming pace pressing for the development of innovative personalized approaches to treating this disease. The absence of clinical symptoms in the early stages delays the onset of adequate treatment. Traditional therapies are not always as effective as they should be and do not guarantee long-lasting relapse-free survival. Metastatic cancers pose a particular challenge to healthcare professionals. This review touches upon the immunologic mechanisms underlying the development of malignancies, talks about conventional and innovative therapeutic modalities, such as targeted, gene or specific immunotherapies, and analyzes the literature on the use of different approaches that form a basis for precision oncology.

Keywords: cancer, nonspecific immunotherapy, cytokine therapy, targeted therapy, monoclonal antibodies, immune checkpoints, cancer vaccines, gene therapy, nanotechnologies, precision medicine

Author contribution: Slavyanskaya TA conceived and planned this review, collected, analyzed and interpreted literature data, reviewed the manuscript, provided images, and wrote conclusions. Salnikova SV collected and analyzed literature data and prepared the draft of the manuscript.

$\triangle$ Correspondence should be addressed: Tatiana A. Slavyanskaya

Miklouho-Maclay 6, Moscow, 117198; tslavyanskaya@gmail.com

Received: 24.08.2018 Accepted: 25.03.2019 Published online: 31.03.2019

DOI: $10.24075 /$ brsmu.2019.018

Проблема борьбы с онкологическими заболеваниями остается приоритетной во всем мире. В последние десятилетия достигнуты несомненные успехи в лечении различных заболеваний [1-3], в том числе злокачественных [4-10]. Достижения в области молекулярной биологии, генетики и иммунологии способствовали выявлению иммуногенетических и иммунобиологических особенностей различных опухолей, пониманию роли врожденного и адаптивного иммунитета в противоопухолевой защите. Результаты проведенных работ убедительно показали, что эффективность иммунотерапии зависит от иммунологической составляющей опухоли. Новые исследования, направленные на понимание иммунных механизмов развития рака и процессов, происходящих в микроокружении опухоли [11], позволили изменить подходы к терапии злокачественных новообразований, поменять стратегию лечения [12-14]. Комплексный подход к терапии, поиск новых мишеней, разработка инновационных методов и способов персонифицированной терапии могут способствовать успешному и результативному лечению рака различной локализации $[4,5,15,16]$.

\section{Роль врожденного и адаптивного иммунитета в противоопухолевой защите}

Реакция иммунной системы при развитии рака (цикл ракиммунитет) характеризуется быстрой пролиферацией раковых клеток, что прежде всего связано с нарушением иммунологической противоопухолевой защиты и «ускользанием» опухоли от иммунологического надзора. Три фазы опухолевого процесса - устранение, равновесие и побег - либо контролируют рак, либо поддерживают его прогрессирование. Устранение включает эффективный ответ Т-клеток, направленный на разрушение опухоли. Локальное развитие опухоли происходит в равновесной фазе, в течение которой неполный контроль иммунной 
системой позволяет злокачественным клеткам сохраняться, расти и подвергаться значительным мутациям. Ингибирующая энергия Т-клеток приводит к фазе побега: локальному прогрессированию и метастазированию [17-19].

\section{Врожденный иммунитет}

В элиминации опухолевых клеток принимают участие натуральные киллеры (NK), натуральные киллеры с Т-клеточным рецептором (NKT), гамма-дельта-Т-клетки ( $(\delta-T)$, макрофаги и гранулоциты.

Ключевую роль в неспецифической элиминации опухолевых клеток играют NK-клетки. Регуляция их функций осуществляется за счет цитокинов (IL2, IL15), костимулирующих молекул (CD40, CD70, CD80, CD86, ICOS), активирующих рецепторов (NKp30, NKp44, NKp46, NKp80), которые наряду с продукцией IFNy и перфоринов реализуют эффекторные функции NK и ингибирующих рецепторов (KIR, CD94) [18, 19].

NKT-клетки представляют собой субпопуляцию лимсоцитов, экспрессирующих как маркеры NK-клеток, так и Т-клеточные дифференцировочные антигены. Для реализации их эфффекторных функций требуется присутствие гранулоцитарно-макрофагального колониестимулирующего фактора (GM-CSF) и IL12 [20]. NKT-клетки служат важнейшими регуляторами иммунного ответа, способствуя защите организма от возникновения, роста и метастазирования опухолей.

Интеграцию врожденного и адаптивного иммунитета осуществляют үठ-Т-клетки, локализующиеся в эпителии кожи, желудочно-кишечного тракта и мочеполовой системы. Они могут играть роль антигенпредставляющих клеток (АПК) [18].

Роль гранулоцитов и макрофрагов оценить на ранних стадиях канцерогенеза не представляется возможным. На поздних стадиях макрофаги поддерживают рост опухоли [18].

\section{Адаптивный иммунитет}

Ключевым моментом в работе адаптивного иммунитета является презентация антигена АПК, в роли которых в абсолютном большинстве случаев выступают дендритные клетки (ДК). Однако презентировать антиген могут также клетки эндотелия, В-лимфоциты и даже сами опухоли [19]. Определенную роль ДК играют также в индукции и поддержании толерантности к собственным антигенам.

В норме для адекватного иммунного ответа необходимо контактное и дистантное взаимодействие ДК и Т-хелперов (Th). Контактное взаимодействие осуществляется группой молекул на мембране Т-клетки. В частности, происходит последовательное взаимодействие CD2, главного комплекса гистосовместимости класса ॥ (MHC ॥) в комплексе с антигеном, CD40, ICAM I, CD 80/86, CD 83 на поверхности АПК с соответствующими им молекулами на поверхности Th: CD58, TCR, CD154, CD11a/CD18, CD28, CD152.

Передачу сигнала внутрь клетки осуществляет группа вторичных мессенджеров, среди которых наиболее изучены система инозитол-3-фосфата, кальмодулинкальциевая система, а также группа киназ, связанных с Т-клеточными рецепторами. В результате прямого и опосредованного взаимодействий происходит активация Th1 и Th2 и соответственно клеточного и гуморального звеньев иммунитета.

С точки зрения противоопухолевой защиты более важно клеточное звено иммунитета. Т-лимфоциты экспрессируют большое количество рецепторов, которые известны тем, что стимулируют или ингибируют активацию этих клеток (рис. 1). Относительное вовлечение данных рецепторов определяет конечный результат такой активации. Эти коингибиторные рецепторы Т-клеток, а также моноклональные антитела (МкАТ), блокирующие ингибиторные молекулы на иммунокомпетентных и опухолевых клетках, стали объектом исследования многих ученых с целью повышения эффективности противоопухолевого иммунного ответа.

Однако в некоторых работах in vivo показано, что антителозависимая клеточная цитотоксичность также вносит определенный вклад в деструкцию опухолевых клеток. На более поздних стадиях опухолевой прогрессии гуморальное звено иммунитета препятствует деструкции опухолевых клеток [18, 19].

Опухоль, особенно на ранних этапах развития, не является для организма чужеродной и в большинстве случаев не содержит антигенов, которые существенно отличали бы ее от нормальных тканей.

Фаза равновесия характеризуется интенсивным ростом опухоли и активацией процессов ангиогенеза. В микроокружении опухоли появляются ДК и макрофраги. Эта фаза характеризуется образованием опухолевого клона из трансформированных раковых клеток и опухоли. В этот период иммунологические реакции аналогичны таковым в фазе надзора, однако процессы канцерогенеза превалируют над защитными механизмами, в связи с чем наблюдается постепенное увеличение объема опухолевой массы.

Фаза ускользания характеризуется сдвигом цитокиновой регуляции в сторону иммуносупрессии, дисбалансом между эффекторными и супрессорными иммунокомпетентными клетками, наличием молекулярных десектов на стадиях распознавания, презентации антигена и трансдукции сигнала внутрь клетки [19].

Цитокины - регуляторные пептиды, продуцируемые клетками организма. Трансформирующий ростовой фактор бета TGF- $\beta$ (TGF- $\left.\beta_{\perp-3}\right)$ - регуляторный пептид, участвующий во многих биологических процессах, включая канцерогенез, заживление ран и поддержание иммунологического гомеостаза. TGF- $\beta$ s реализует свои биологические функции посредством серин-треониновых

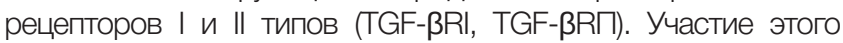
цитокина в формировании иммунологической толерантности обусловлено его влиянием на $\mathrm{CD}^{+}{ }^{-}, \mathrm{CD}^{+}-$лимфоциты и NK-клетки. TGF- $\beta$ способствует сдвигу направления дифференцировки $\mathrm{CD}^{+}$в сторону преобладания иммунорегуляторных клеток $\left(\mathrm{CD} 4^{+} \mathrm{CD} 25^{+}\right.$Т-регуляторных клеток или естественных Treg), подавляет экспрессию перфоринов, гранзима B и FAS-лиганда в CD8+-лимфоцитах, блокирует IL12-индуцированную экспрессию IFN-r NK [20-22].

Интерлейкин IL10 реализует свои функции посредством рецепторов двух типов IL10R1 и IL10R2, локализованных на ДК и Th. Он блокирует продукцию IL12, костимулирующих молекул, экспрессию антигенов МНС II на ДК, нарушая их созревание, а также синтез цитокинов CD4+-клетками [19]. Гетеродимер IL23 состоит из двух субъединиц, одна из которых (р40) аналогична таковой у IL12. Как IL23, так и IL12 продуцируются клетками, относящимися к системе врожденного иммунитета, но регулируют функционирование компонентов адаптивного иммунитета. IL12 способствует созреванию Т-лимфоцитов и индуцирует продукцию IL6, IL15, IL18, TNFß, GM-CSF, в то время как IL23 способствует дифференцировке незрелых клеток 
в Th17 и синтезу IL17, IL17F, IL6, TNFa. Кроме того, в ряде работ показано, что IL23 способствует стимуляции ангиогенеза за счет увеличения экспрессии матриксной металлопротеиназы 9-го типа (MMP9) [18, 19, 22].

Наиболее важным проангиогенным фактором, продуцируемым как опухолью, так и иммунокомпетентными клетками, служит сосудистый эндотелиальный фрактор роста (VEGF). В настоящее время известно семь изоформ, из которых VEGF-a наиболее значим для процессов ангиогенеза и иммуномодуляции. VEGF подавляет созревание ДК, а также способствует генерации незрелых миелоидных клеток (iМC), которые в свою очередь подавляют Т-клеточную активность [19].

Главное «Поле битвы» иммунной системы и опухоли ее микроокружение. В фразе ускользания отмечается увеличение доли незрелых ДК и супрессорных Т-регуляторов (Treg) в общей популяции. Зрелые ДК экспрессируют на своей поверхности CD40, CD80, CD83, CD86 и характеризуются высоким уровнем продукции IL12. Под действием VEGF, IL6, TGF- $\beta$, IL10, COX-2, PGE2, ганглиозидов, находящихся в микроокружении опухоли, блокируются дифференцировка и созревание ДК, что делает невозможным формирование адекватного иммунного ответа [19].

Регуляторные Т-клетки относятся к системе адаптивного иммунитета и созревают из незрелых Т-клеток. Они подавляют иммунный ответ путем регуляции функций эффекторных клеток. В настоящее время выделяют три типа Treg: $\mathrm{CD} 4^{+} \mathrm{CD} 25^{+} \mathrm{Foxp}^{+}$и две разновидности индуцированных Treg: Treg1 и Treg2 (последние обозначали ранее как Тh3). Кроме того, имеются супрессорные клетки с фенотипом CD8+, однако их функция не до конца понятна. Наибольшую роль в иммуносупрессии у онкологических больных играют $\mathrm{CD} 4{ }^{+} \mathrm{CD} 25^{+}$Treg- клетки, берущие свое начало в костном мозге. Их высокую концентрацию выявляют у больных раком молочной железы, колоректальным раком, раком легкого, поджелудочной железы. Образуются они из тех же клетокпредшественниц, что и Th, под влиянием избыточных концентраций TGF- $\beta$, IL10 и VEGF. Механизм супрессивного действия $\mathrm{CD} 4{ }^{+} \mathrm{CD} 25^{+}$Treg-клеток связан с секрецией супрессорных цитокинов (TGF- $\beta$, IL10), с «конкуренцией» в отношении лигандов (IL2), индукцией толерантности ДК и в ряде случаев с их прямым лизисом [23].

Третьей характерной особенностью фазы ускользания является наличие молекулярных десектов ДК и лимфоцитов. В частности, обнаружено снижение уровня экспрессии молекул МHC классов I и II, CD80, CD86, CD154 на поверхности АПК из опухоли, а также छ-цепи TCR Th [23].

Кроме нарушений функциональной активности лимфоцитов, выявлены изменения экспрессии и состава интегринов на опухолевых клетках, что может способствовать как уменьшению силы их взаимодействия между собой, так и неоангиогенезу. На поверхности опухолевых клеток нарушен также синтез селектинов (CD44, ELAM-1), что коррелирует с плохим прогнозом заболевания.

Одним из основных факторов, подавляющих функции лимсоцитов, находящихся в микроокружении опухоли, являются ганглиозиды (GD1a, GD2, GD3, GM1, GM2), экспрессирующиеся на поверхности опухолевых клеток и слущивающиеся в межклеточное пространство. Они обладают способностью подавлять функции лимфоцитов, инсильтрирующих опухоль (TIL), вмешиваясь в процессы трансдукции сигнала внутрь клетки. Нарушения эффекторной функции лимфоцитов проявляются В виде снижения уровня экспрессии гранзима В и киназ, находящихся в комплексе с TCR-p59fyn и ZAP-70.

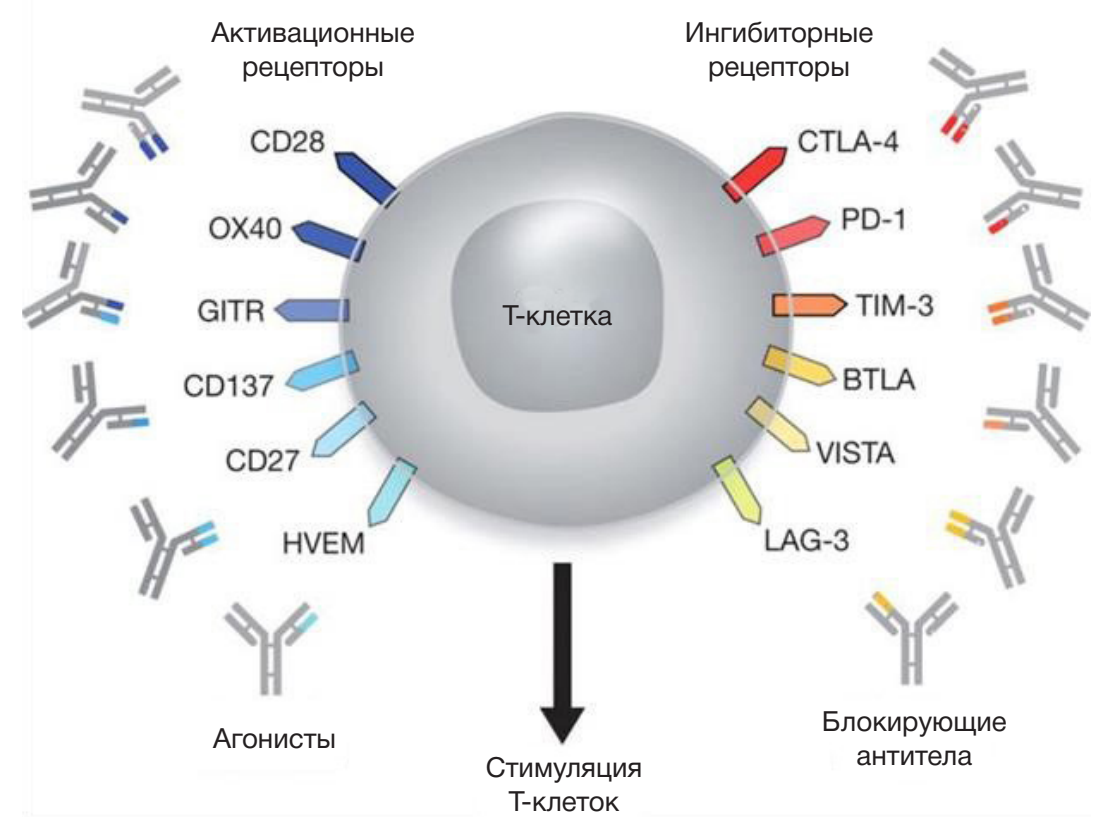

Рис. 1. Активационные и ингибиторные рецепторы Т-клеток [21]. Т-лимфоциты экспрессируют большое количество рецепторов, которые известны тем, что стимулируют или ингибируют активацию этих клеток. Относительное вовлечение этих рецепторов определяет конечный результат такой активации. Ингибиторные рецепторы: CTLA-4, или антиген-4 цитотоксических Т-лимфоцитов, - негативный регулятор активации Т-клеток; PD-1, или рецептор-1 запрограммированной смерти клетки, - играет важную роль в отрицательной регуляции иммунной системы посредством предотвращения активации Т-лимфоцитов, что снижает аутоиммунность и повышает аутотолерантность; TIM - Т-клеточный иммуноглобулин и муциновый белок; ВТLА, или В- и Т-лимфоцитарный аттенюатор, - антиген, ослабляющий функции В- и Т-лимфоцитов, участвует в регуляции лимфоцитов во время иммунного ответа. Продукт гена человека BTLA. Экспрессия BTLA индуцируется при активации Т-лимфоцитов и остается на клетках Th1, но не Th2; VISTA - иммуноглобулиновый супрессор активирования T-клеток V домена; LAG-3 (CD223) - ген активации лимфоцитов. Активационные рецепторы: CD28 - костимуляторный рецептор; OX40 - костимуляторный рецептор; GITR — глюкокортикоид-индуцированный рецептор к ФHO; CD137 — костимуляторный рецептор; CD27 костимуляторный рецептор; HVEM - мембранный белок, рецептор из надсемейства рецепторов факторов некроза опухоли 14 (TNFRSF14), медиатор проникновения вируса герпеса 
Среди интегральных показателей функционирования иммунной системы наиболее значимы снижение пролиферативного индекса, экспрессии $\alpha$ - и $\beta$-субъединиц рецептора IL2, степень фосфорилирования белка, кодируемого геном Rb. Все эти изменения характерны как для периферических лимфоцитов, так и для клеток, инфильтрирующих опухоль, однако выражены они в разной

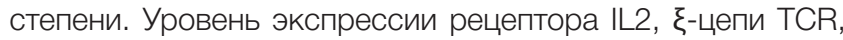
CD54, а также некоторых других показателей составляет примерно 80\% для периферических лимфоцитов (от уровня этих показателей, соответствующих здоровым людям) и 30\% для лимфоцитов, инсильтрирующих опухоль. Это подтверждает тот факт, что данные изменения носят вторичный характер по отношению к опухоли [23].

Описанные выше изменения характерны для иммунной системы больных с локально распространенными и диссеминированными формами опухолей.

Таким образом, иммунной системе принадлежит решающая роль в борьбе со злокачественными новообразованиями. Общая иммунодепрессия при онкологических заболеваниях имеет многофакторное происхождение и обычно сочетается со способностью клеток опухолевого клона активно противостоять воздействию эффекторов иммунной системы. Вместе с тем, понимание ключевых патогенетических механизмов, лежащих в основе развития опухоли, ее «ускользания» от иммунобиологического контроля, стали отправной точкой для создания нового направления в онкологии специфической иммунотерапии, лежащей в основе прецизионного лечения.

\section{Инновационные методы лечения злокачественных новообразований}

Идея использования неспецифической иммунотерапии (НИТ) при лечении онкозаболеваний зародилась давно. С целью профилактики рецидивов при неинвазивном уротелиальном раке (УР) на протяжении многих десятилетий применяют БЦЖ-вакцину - стандартный метод HИТ (Б-НИT), либо ее комбинации c IL или aHти-IL моноклональными антителами (МкАТ к IL) [6, 24]. Установлено, что Б-НИТ в сочетании с представителями семейства toll-подобных рецепторов (TLR2, TLR4, TLR9, TRAIL) приводит к уменьшению количества рецидивов. В клинических испытаниях перспективными были также признаны и агонисты TLR7 и TLR9 [25].

В настоящее время все большее внимание уделяют адаптивной специфической иммунотерапии - методу, основанному на введении в организм пациента собственных клеток иммунной системы, активированных in vitro [6].

Прорывом в лечении онкологических больных стала таргетная терапия с использованием МкАТ. Ее проводят с помощью препаратов, мишенями для которых служат ростовые факторы и рецепторы, экспрессируемые раковыми клетками [26]. Для многих опухолей человека характерны высокие уровни ростовых факторов и их рецепторов, что активно используют в качестве потенциальных терапевтических мишеней для таргетной терапии. Так, в настоящее время изучают противоопухолевое действие препаратов, влияющих на ангиогенез, например VEGF, рецептор эпидермального фактора роста (EGFR) и др. [27].

Повышено внимание при терапии рака к ингибиторам ангиогенеза, однако мало что известно об их действии на сосуды опухоли. Результаты исследований по оценке ингибиторов VEGF (AG013736 и Vegf-Trap) показали, что эти препараты останавливают ангиогенез или вызывают регрессию существующих опухолевых сосудов. Лечение ими вызвало надежные и ранние изменения в эндотелиальных клетках, перицитах и базальной мембране сосудов при спонтанных опухолях островков РИП-Таг2 трансгенных мышей и при подкожно имплантированных карциномах легких Льюиса. Было отмечено уменьшение сосудистой плотности более чем на $70 \%$, а оставшиеся эндотелиальные клетки приобрели нормальный фенотип, в них уменьшилась экспрессия EGFR [27].

Несомненный интерес для онкологии представляют интегриновые белки, облегчающие связь между клетками и их внеклеточной средой и контролирующие клеточную пролиферацию, выживание, миграцию и адгезию [28]. Понимание роли интегринов, значения уровня их экспрессии для иммунного контроля над опухолью, является активной областью исследований иммунотерапии. В настоящее время клинические испытания проходят несколько МкАТ, нацеленных на интегрины, - этаразицумаб, циленгитид [29, 30]. В I фазе клинических испытаний этарацизумаб (МкАТ против интегрина аvß3) показал свою эффективность при лечении многих опухолей, однако в исследованиях II фазы эффективность препарата не была подтверждена [29]. Циленгитид (МкАТ к интегринам аvß3 и аvß5) показал эффективность и хорошую переносимость в | и || фазах клинических испытаний для лечения глиобластом, причем 69\% имели безрецидивную выживаемость в течение 6 месяцев [31].

В дополнение к интегринам в качестве терапевтических мишеней исследуют другие молекулы, участвующие в клеточной передаче сигналов, которые подавляют иммунную функцию в микроокружении опухоли. На многих лейкоцитах обнаружен интегрин-ассоциированный белок CD47 - белок мембранного рецептора клеточной поверхности. Он связывается с бета-3-интегрином, тромбоспондином-1, сигнальным регуляторным белкомальфа (SIRP-a) и другими сигнальными белками для регулирования активации Т-клеток, миграции клеток, фагоцитоза и других функций иммунных клеток. CD47 экспрессируется не только во многих опухолях, но и в раковых стволовых клетках, что позволяет последним выживать, приводя к поздним рецидивам. Использование CD47 с МкAT в мышиных моделях оказалось эффективным при лечении острого лимфоцитарного лейкоза, острого миелоидного лейкоза и лейомиосаркомы. В настоящее время проходит I фаза клинических испытаний в нескольких исследованиях с оценкой ингибирования CD47 у пациентов с УР, острым миелоидным лейкозом [32].

Рецепторы фактора некроза опухолей (TNF-R), включая индуцированные глюкокортикоидами TNF-R (GITR, CD357), CD27, OX40 (CD134) и 4-1BB (CD137), представляют собой семейство белков, ответственных за трансдуцирование дополнительных костимулирующих сигналов, необходимых для активации Т-лимфоцитов, участвующих в уничтожении опухолевых клеток. Для использования этого важного сигнального каскада были разработаны МкАТ-агонисты и специфические комплексы лигандов, которые могут взаимодействовать с TNF-R и активировать последующие реакции [33]. Завершена I фаза клинических испытаний препарата варлилумаб - агониста lgG1 человека, который направлен против CD27 (aCD27). В экспериментальных исследованиях на мышах было продемонстрировано, что его сочетание с антиPD-1 приводит к 100\%-й элиминации опухоли благодаря способности аCD27 стимулировать 
цитотоксические Т-лимфоциты (ЦТЛ). Этот ответ намного сильнее, чем результат двойной терапии с помощью aPD1/aCTLA-4 [33].

Определенный интерес представляет рецептор колониестимулирующего фактора 1 (CSF1R) - поверхностный клеточный рецептор, экспрессируемый преимущественно макрофагами и моноцитами. Лигирование CSF1R способствует активации макрофагов (M) и трансформации их в сторону фенотипа М2 (участвуют в Т-хелперных иммунных реакциях 2-го типа, стимулируют процессы пролиферации и ангиогенеза), поэтому блокирование CSF1R или истощение клеток, экспрессирующих CSF1R, обусловливает развитие противоопухолевых макросрагов фенотипа M1 (способствуют выработке провоспалительных цитокинов, цитотоксических молекул и помогают реализовать Т-хелперные иммунные реакции 1-го типа). Эффективность методики была показана в исследованиях на животных [34]. В настоящее время проводят | и || фазы клинических испытаний ингибитора малых молекул CSF1R (PLX3397, Плексикон) в сочетании c пембролизумабом у пациентов с прогрессирующими раковыми заболеваниями. Были также получены МкАТ, нацеленные на CSF1R (FPA008, Five Prime Therapeutics, Emactuzumab, Hoffmann-La Roche).

Успешная иммунотерапия невозможна без понимания процессов, происходящих в опухолевом микроокружении, где одним из важных факторов является уровень инфильтрации опухоли Т-клетками. В оценке уровня может помочь изучение связанных с опухолью макрофагов, сосудистых эндотелиальных клеток, фибробластов и иммуносупрессивных метаболитов, например кинуренина [7]

Одним из сильнейших иммуносупрессоров опухолевого микроокружения являются Treg-клетки. Их ингибирование проводили с помощью МкАТ и ДК-вакцин [7]. Они накапливаются в крови, асцитической жидкости, метастазах и первичных опухолях. Клинические исследования даклизумаба, сорафениба, сунитиниба и иматиниба показали снижение количества Treg, что коррелировало с выживаемостью пациентов [7, 8]. Ряд исследователей изучали результаты сочетания Treg с инсрильтративными супрессорными клетками, полученными из миелоидов (MDSC), при подавлении противоопухолевого иммунного ответа у пациентов с почечно-клеточным раком и саркомой мягких тканей [8]. В доклиническом исследовании была показана чувствительность MDSC к агонисту TRAILрецептора 2 (TRAIL-R2). Результаты I фразы клинических испытаний показали, что использование TRAIL-R2 (DS-8273a) для лечения распространенных форм УР, меланомы, гепатоцеллюлярной карциномы привело к эффективному уменьшению количества MDSC в 50\% случаев, не влияло на количество нейтрофилов, моноцитов и других популяций миелоидных и лимфоидных клеток. Уменьшение MDSC обратно коррелировало с продолжительностью жизни пациентов без прогрессирования заболевания [7, 8].

Снижению количества Treg в периферической крови и смещению иммунного баланса к стимулирующей среде способствуют ингибиторы тирозинкиназ (сорафениб). Неоадъювантная терапия сорафенибом привела к значительному снижению процента тумор-инсильтрирующих Treg в сравнении с пациентами, не получавшими сорафениб: в среднем 17,3\% против 28,1\%, ( $p=0,046)$ [35]. В клинических исследованиях отмечено также снижение активности Treg на фоне приема даклизумаба, сорафениба, сунитиниба и иматиниба при лечении рака почки, лейкозов, гастроинтестинальных стромальных опухолей [36, 37].

Исследования, направленные на изучение микроокружения опухоли, показали важную роль молекул межклеточной адгезии. Нарушения межклеточной адгезии характерны для большинства злокачественных опухолей эпителиального

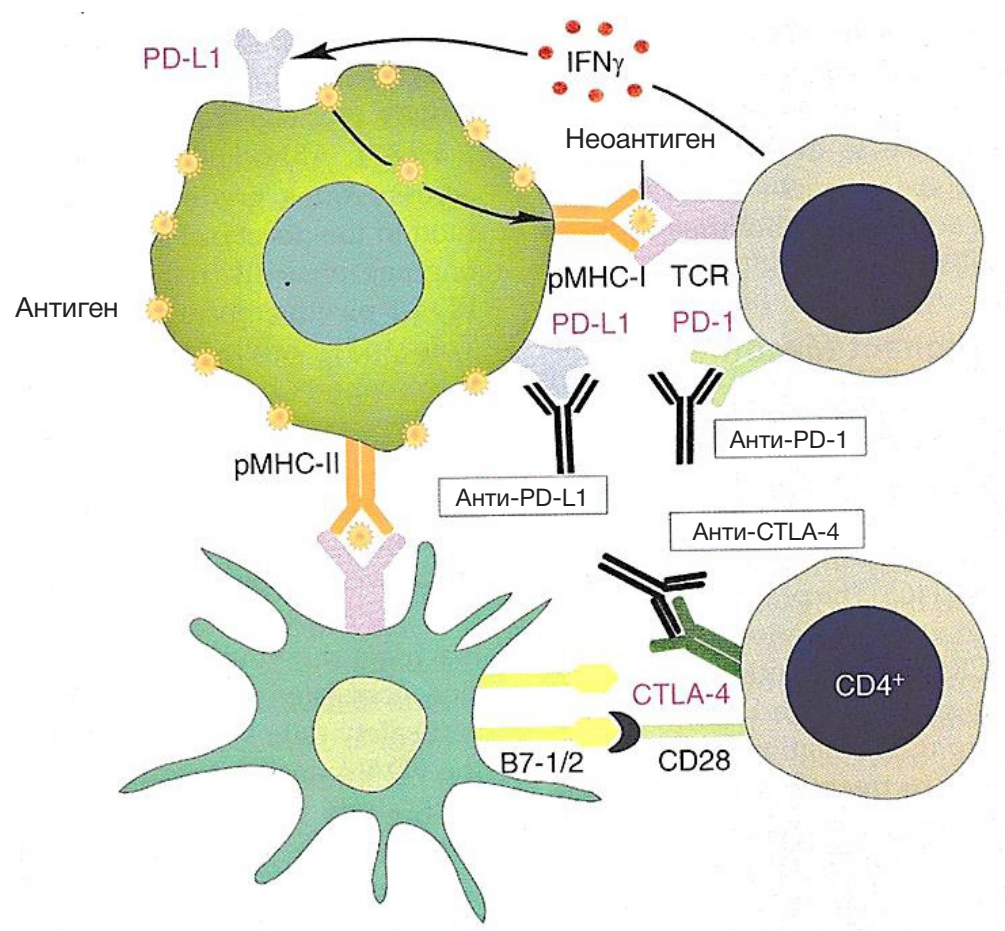

Рис. 2. Механизм распознавания неоантигена и блокада контрольных точек [42]. Анти-PD-1, анти-PDL-1 и анти-CTLA-4-антитела работают путем блокирования путей, что приводит к распознаванию неоантигена и активации Т-клеток. CD4+ - T-клетки, экспрессирующие антиген кластера дифференцировки 4 (CD4), специфичны антигенам MHC класса II; CD28 - Т-клетки, экспрессирующие антиген кластера дифференцировки 28; CTLA-4 — антиген 4, ассоциированный с цитотоксическими Т-лимфоцитами; IFN - интерферон; PD-L1 - лиганд-1 к рецептору запрограммированной клеточной гибели; PD-1 - рецептор запрограммированной клеточной гибели; рMHC - пептидный рецептор главного комплекса гистосовместимости, комплементарный к TCR; TCR Т-клеточный рецептор 
происхождения. Ключевым компонентом межклеточных адгезионных контактов в эпителиальных тканях является Е-кадгерин. Утрата экспрессии Е-кадгерина наблюдалась почти в 85\% случаев долькового рака молочной железы, а резкое угнетение его экспрессии отмечено также в карциномах пищевода и желудка, гепатокарциномах [38]. Сохранение экспрессии Е-кадгерина характерно для медленно растущих и доброкачественных новообразований. Считается, что угнетение или утрата экспрессии Е-кадгерина коррелирует с инвазивностью опухоли, формированием отдаленных метастазов и неблагоприятным клиническим прогнозом [39].

Открытие регуляторных молекул, ответственных за предотвращение избыточной активации Т-лимфоцитов и их запрограммированную гибель, положило начало инновационному методу таргетной иммунотерапии, названному блокадой иммунных контрольных точек (БИКТ), или иммунных чек-поинтов. В настоящее время использование иммунных чек-поинтов для таргетной терапии стало стандартом лечения многих злокачественных опухолей. Исследователи применяли неоадъювантные и адъювантные схемы терапии. Опухоли с одной и той же гистологической картиной демонстрировали широкий спектр гетерогенности в том, как они подавляли иммунную систему, причем опухоли изменяли экспрессию PD-1 или имели разные количества инфильтрирующих лимфоцитов в микроокружении опухоли [40, 41]. БИКТ используют для того, чтобы заблокировать системы контроля и восстановить противоопухолевый иммунный ответ (рис. 2). K таким препаратам относятся: анти-CTLA-4 (ипилимумаб), анти-PD-1 (пембролизумаб и ниволумаб) [43] и антиPD-L1 (авелумаб, атезолизумаб), показавшие высокую эффективность в лечении многих злокачественных новообразований, в том числе метастатического УР. Успех терапии ингибиторами PD-1 и PD-L1 при различных формах рака подчеркивает универсальность действия иммунотерапии. В клинических испытаниях эти препараты показали хорошие результаты и на сегодняшний день стали стандартом лечения нескольких видов онкологических заболеваний.

В настоящее время установлено, что использование В лечении сочетанного воздействия стандартной химиотерапии (XT) и ипилимумаба приводило к увеличению активности CD4+- и CD8 ${ }^{+}-$-лимфоцитов, выработки провоспалительных цитокинов (IL2, IL12) и GM-CSF [44]. Однако из-за токсичности ипилимумаба его применение в лечении УР может быть ограничено. Пембролизумаб одобрен для использования в | и || линии терапии метастатического УР, тогда как ниволумаб - только для ॥ линии, после ХТ на основе платины [9].

В клинических исследованиях было выявлено, что пути PD-1 и CTLA-4 играют нерегулярную роль в ингибировании иммунных реакций $[10,45]$. Показана эффективность комбинированной терапии ниволумабом и ипилимумабом у пациентов с метастатической меланомой, в сравнении с монотерапией, в связи с чем в 2016 г. использование комбинированной терапии этими препаратами было одобрено для неоперабельной или метастатической меланомы [43]. Прошли клинические испытания и разрешены к использованию дурвалумаб и авелумаб ингибиторы анти-PD-L1 [46].

Иммунотерапия злокачественных новообразований МкАТ-агонистами 4-1ВВ выявила возможность элиминации опухоли in vivo [33]. В настоящее время проходят испытания препараты урелюмаб (МкАТ изотипа IgG4) и утомилюмаб (МкАТ изотипа IgG2), являющиеся полностью МкАТ-агонистами против 4-1BВ (a4-1ВВ) человека [33, 47]. С целью фокусирования иммунных реакций на опухолевые клетки разработан комплексный препарат PRS-343, состоящий из МкAT-агонистов 4-1BB и MкAT к HER2 (трастузумаб) [33].

Одним из направлений является исследование индуцирования противоопухолевого иммунного ответа путем активации генов сигнальных путей врожденного иммунитета через STING (трансмембранный белок 173, помогающий регулировать активность иммунной системы за счет стимулирования продукции интерферонов I типа IFN-I) и TLR. В доклинических испытаниях было показано, что TLR увеличивают секрецию цитокинов, индуцирующих иммунный ответ через клетки Лангерганса, макрофаги и лимфоциты, а также стимулируют пролиферацию Т-клеток через путь протеинкиназы. В то же время агонисты TLR ингибируют рост опухоли, противодействуя подавлению иммунной системы в микроокружении опухоли [48]. Клинические исследования показали, что агонист TLR Имиквимод в 72\% случаев эффективен в лечении нескольких видов рака (глиомы, меланомы, рака молочной железы) [49]. Наряду с этим имеются данные о применении агонистов TLR в качестве адъювантов для противоопухолевых вакцин [18, 49-51].

В последнее время проводят активные исследования по изучению рецептора химерного антигена (CAR) Т-клеток, представляющего собой мембранный рецептор, способный связываться с определенным опухолевым антигеном, и содержащий внутриклеточный компонент, который активирует Т-клетку в присутствии антигена [52]. Было показано, что CAR-T-клетки способны активировать костимуляторный сигнал (для CD28 или CD137), который активирует Т-клетки и приводит к устойчивому иммунному ответу [53].

Другая стратегия - комбинированная иммунотерапия, включающая использование онколитических вирусов, например аденовирусов, экспрессирующих CD40L и 4-1BBL. Она предназначена для развития противоопухолевого иммунитета при введении в микроокружение опухоли агентов, способных стимулировать Т-клеточные реакции самостоятельно или в сочетании с другими иммунологическими препаратами [54]. Создание активной комбинации препаратов, влияющих на клетки конкретной опухоли, представляет определенные проблемы.

Так, продолжаются исследования различных комбинаций с целью определения их оптимального взаимодействия (на примере модели рака предстательной железы и саркомы): МкAT-агонист OX40 в комбинации с атезолизумабом (APD-L1); МкAT-агонист OX40 с бевацизумабом (рекомбинантные гуманизированные анти-VEGF-МкAT), МкAT-агонист OX40 (PF-04518600) с МкAT-агонистами а4-1BB (NCT02315066) [55]. Авелумаб (МкAT aPD-L1) используют в нескольких вариантах: комбинация А (авелумаб и агонист 4-1BВ, PF-05082566); комбинация В (авелумаб и МкАТ-агонист OX40, PF-04518600); комбинация C (авелумаб и МкАТ к колониестимулирующему фактору 1, PD 0360324); комбинация Д (авелумаб и МкАТ-агонисты 4-1BВ и МкAT-агонисты OX40, NCT02554812). Показано, что комбинированная иммунотерапия МкАТ-агонистами ОХ40/ CTLA-4 повышает выживаемость и способствует регрессии опухоли [56, 57]

Проводятся исследования । фазы у пациентов с меланомой III/IV стадии с использованием следующей комбинации: гуманизированные МкАT изотипа IgG1, не 
содержащие аминокислоты aglycosyl IgG1 (агонист GITR, от англ. Glucocorticoid-induced tumor necrosis factor receptor - глюкокортикоид-индуцированный рецептор к фактору некроза опухоли), с ниволумабом или ипилимумабом, либо их комбинация [58].

Интересной представляется комбинация, включающая GR-MD-02, - препарат, который специфически ингибирует Галектин-3. Галектин-3 относят к маркерам опухолевой трансформации клеток, участвующим в регуляции всех процессов опухолевой прогрессии. Он активируется при раке многих локализаций, а уровень его экспрессии коррелирует с метастатическим потенциалом и плохим прогнозом заболевания. Кроме того, Галектин-3 может играть определенную роль в подавлении иммунитета Доклинические испытания показали, что добавление GR-MD-02 к МкAT-агонисту OX40 или к ингибирующим контрольным точкам приводит к увеличению случаев выживаемости и регрессии опухоли по сравнению с применением одной только иммунотерапии [56]. Эти данные послужили основанием для проведения I фазы клинических испытаний у пациентов с распространенным раком тестированию блокатора GR-MD-02 с ипилимумабом или пембролизумабом (NCT02117362, NCT02575404) [33]

По мнению исследователей, перспективной молекулой для терапевтического вмешательства может служить индоламин-2,3-диоксигеназа 1 (IDO1). Она снижает пролиферацию Т-клеток и увеличивает неоваскуляризацию, противодействуя гамма-интерферону [59]. В связи с этим проводят испытания комбинаций ингибиторов IDO1 с другими иммуномодулирующими агентами, включая исследование фазы III в меланоме с ингибитором PD-1 пембролизумабом [60].

Поздние стадии онкологических заболеваний, как правило, ассоциируются с гиперэкспрессией EGFR опухолевыми клетками. Были проведены II и III фазы клинических испытаний по оценке эффективности препарата цетуксимаб (C225), представляющего собой рекомбинантное химерное МкАТ, обладающее высокой специфичностью к внеклеточному домену EGFR и способное конкурировать с естественными лигандами (EGF; TGF- $\alpha$ ) за связывание с рецептором. Препарат синтезирован на основе мышиного МкАТ M225, к которому для снижения иммуногенности присоединили фрагмент человеческого lgG1. Была оценена возможность использования этого препарата как в монорежиме, так и в комбинации с цисплатином. У двух из 52 пациентов с прогрессированием заболевания головы и шеи зарегистрированы частичные ремиссии [61].

Несмотря на успех таргетной терапии, не у всех пациентов достигается полный терапевтический эффект, что диктует необходимость разработки других, более эффективных методов лечения. Создание противоопухолевых вакцин и использование онколитических вирусов для усиления специсического иммунного ответа к опухоли путем увеличения процесса представления антигена Т-клеткам являются новым, инновационным научным направлением, способствующим повышению эффективности противоопухолевого лечения $[33,54]$.

Использование цельноклеточных вакцин, представляющих собой опухолевые клетки, лишенные способности делиться, в экспериментах на лабораторных животных вызывало хороший противоопухолевый иммунный ответ, однако клинические испытания не были столь успешными [13, 62, 63].

Активно изучают пептидные вакцины на основе синтетического пептида Сурвивина, комплекса специфических опухолеассоциированных пептидов, а также NY-ESO-1 + GM-CSF с адьювантом в виде Б-НИТ. Использование персонализированной пептидной вакцины (PPV), состоящей из комбинации четырех пептидов, способствовало двукратному повышению выживаемости пациентов [54, 63].

В экспериментальных исследованиях на мышах предпринимают попытки объединить вакцины на основе ДК с костимуляторным агонистом анти-ОХ40 или с МкАТ анти-4-1ВВ. Первые результаты показали, что комбинированные вакцины давали лучший иммунный ответ по сравнению с ДК-вакцинами у трансгенных мышей Her-2/neu, вплоть до полного исчезновения опухоли [33, 64-67].

Кроме того, проводится II фаза клинических испытаний вакцины Lapuleucel-T на основе ДК с целью оценки выживаемости, безопасности и наличия иммунных реакций у пациентов с высоким риском рецидива болезни (с гиперсекрецией антигена HER-2 + антигена рака мочевого пузыря UBC (NCT01353222) [68].

Аутологичные ДК-вакцины могут инициировать и усиливать опухолевые антиген-специфичные реакции путем активации как Тh, так и ЦТЛ [67]. Это направление противоопухолевой иммунотерапии активно изучают не только за рубежом, но в нашей стране для лиц с исчерпанными возможностями лечения (метастатические формы рака) [4, 5, 69]. К настоящему времени завершены многочисленные исследования и/или проходят II фазу клинических испытаний вакцины на основе аутологичных ДК при различных формах рака.

Ввиду восприимчивости злокачественных новообразований к иммунотерапии в последнее время в литературе появляются исследования, посвященные разработке противоопухолевых вакцин [70], в частности, на основе раковотестикулярного антигена (NY-ESO-1), синтетического пептида (Сурвивина) или его сочетания c IFNa, ДК с дополненной блокадой костимулирующей молекулы B7-H1(PD-L1) [71]. Однако эти исследования носят единичный характер, находятся на стадии разработки и не имеют широкого клинического применения.

Наномедицина с помощью прогрессивных нанотехнологий предлагает уникальные подходы к лечению больных раком новыми препаратами для XТ или иммунотерапии. Так, в ряде работ наночастицы $\left(\mathrm{HЧ}^{4}\right.$ использовали для повышения терапевтической эффективности и снижения побочных эффектов XТ путем нацеливания химиотерапевтических агентов на специфическую ткань и увеличения их биодоступности [72, 73].

Предложена новая технология Immunoswitch, в которой МкАТ и МкАТ-агонисты связаны с НЧ [73]. Immunoswitch-HЧ покрыты двумя разными антителами, которые одновременно блокируют ингибирующий чек-поинт PD-L1 сигнал и стимулируют Т-клетки через 4-1BВ костимуляторные пути. Они способны преодолевать иммуносупрессирующее микроокружение опухоли. Исследования in vivo показали существенное замедление опухолевого роста и увеличение выживаемости мышиной меланомы и рака толстой кишки по сравнению с результатами использования растворимых антител и НЧ, отдельно соединенных с ингибиторами и стимуляторами антител. Использование immunoswitchНЧ привело к увеличению плотности, специфичности и функциональности опухоль-инфильтрирующих ЦТЛ [73].

Функционализация НЧ со специфическими МкАТ является многообещающей стратегией для создания комплекса НЧ с МкАТ, целенаправленной его доставки и поглощения опухолевыми клетками, что приведет 
К повышению эффективности лечения и снижению побочных эффектов [73-76].

Однако, несмотря на наличие позитивных противоопухолевых эффеектов, полученных при различных методологических подходах в лечении рака, молекулярные и клеточные механизмы противоопухолевой защиты, позволяющие обеспечить иммунную толерантность, до сих пор не до конца изучены. Одним из новых многообещающих кандидатов для расширения возможности иммунотерапии являются NK-клетки, хотя успех их применения на сегодняшний день ограничивается лечением гематологического рака. В эксперименте на трансгенных мышах было показано, что с использованием активирующего рецептора NKp44 NK-клетки связывают тромбоцитарный фактор роста DD (PDGF-DD), в результате чего рост опухоли прекращался [77]

Генную терапию, в частности CRISPR-технологии (редактирование генома), относят к новому виду лечения онкозаболеваний, многообещающие исследования в этом направлении активно развиваются.

\section{ВЫВОДЫ}

Прецизионная (персонализированная) медицина в онкологии становится реальностью. Таргетная терапия, использование нанотехнологий, терапия блокаторами иммунных чекпоинтов, поиск новых перспективных мишеней и путей преодоления иммунологической толерантности, создание противоопухолевых вакцин, молекулярно-генетические исследования позволят не только диагностировать и лечить онкологические заболевания на ранних их стадиях, но и подобрать адекватную эффективную специфическую терапию при их различных клинических формах, а также улучшать качество жизни больного. На современном этапе в онкологии на первый план выходит прецизионная медицина, которая предусматривает мультидисциплинарный персонализированный пациенториентированный подход к диагностике, лечению и реабилитации онкологических больных. Наступила эра онкоиммунологии, но использование ее достижений возможно только в комплексной терапии, наряду с химио- и таргетной терапией. Наиболее эффективная терапия должна быть назначена на первых этапах лечения, в противном случае шансы пациента получить последующее лечение становятся минимальными. Составляющие эффективного противоопухолевого лечения - это его клиническая эффективность (общая выживаемость, выживаемость без прогрессирования и контроль над болезнью), безопасность (управляемый контроль токсичности), фрармакоэкономическая эффективность, а также качество жизни больного. При каждой локализации опухоли имеется своя приоритетная стратегия противоопухолевой терапии, зависящая от ее биологических особенностей.

\section{Литература}

1. Кудрявцева И. В., Славянская Т. А., Трунов А. Н., Трунова Л. А. Уровни аутоантител к ядерным ДНК, лактоферрина и некоторые иммунологические показатели у больных ревматоидным артритом. Бюллетень Сибирского отделения Российской академии медицинских наук. 1999; 19 (3-4): 66-8.

2. Смирнова Т. А., Пономарева Е. П., Ханферян Р. А., Колесников В. В. Опыт применения ронколейкина при терапии язвенной болезни желудка, ассоциированной с Helicobacter Pylori, в амбулаторных условиях. Терапевтический архив. 2009; 81 (2): 30-5.

3. Славянская Т. А., Сепиашвили Р. И., Вишняков М. Н., Чихладзе М. В. Иммунологический мониторинг больных хроническим бронхитом в динамике восстановительной иммунореабилитации. International Journal on Immunorehabilitation. 1999; (11): 70

4. Славянская Т. А., Авдонкина Н. А., Сальникова С. В. Оптимизация условий получения жизнеспособной первичной культуры клеток уротелиальной карциномы. Аллергология и иммунология. 2016; 17 (3): 176-9.

5. Burger M, Thiounn N, Denzinger S, Kondas J, Benoit G, Chapado MS, et al. The application of adjuvant autologous antravesical macrophage cell therapy vs. BCG in non-muscle invasive bladder cancer: a multicenter, randomized trial. J Transl Med. 2010; (8): 54.

6. Camisaschi C, Vallacchi V, Vergani E, et al. Targeting immune regulatory networks to counteract immune suppression in cancer. Vaccines (Basel). 2016; 4 (4): pii: E38.

7. Dominguez G, Condamine TC, Mony S, et al. Selective targeting of myeloid-derived suppressor cells in cancer patients using DS8273a, an agonistic TRAIL-R2 antibody. Clin Cancer Res. 2016; 23 (12): 2942-50

8. Sharma P, Retz M, Seifker-Radtke A, et al. Nivolumab in metastatic urothelial carcinoma after platinum therapy (Check-Mate 275): a multicentre, single-arm, phase 2 trial. Lancet Oncol. 2017; 18 (3): 312-22.

9. Larkin J, Chiarion-Sileni V, Gonzalez R, Grob JJ, Cowey CL, Lao CD, et al. Combined nivolumab and ipilimumab or monotherapy in untreated melanoma. N Engl J Med. 2015; (373): 23-34.

10. Сепиашвили Р. И., Беляев А. М. Иммунотерапия рака:

проблемы и перспективы. Аллергология и иммунология. 2015; 16 (4): 354-7.

11. Сальникова С. В., Славянская Т. А. и др. Инновационные технологии в лечении рака мочевого пузыря. Аллергология и иммунология. 2016; 17 (1): 21-6.

12. Сальникова С. В., Славянская Т. А. и др. Современные подходы и достижения в лечении рака мочевого пузыря. Аллергология и иммунология. 2016; 17 (1): 50-1.

13. Балдуева И. А., Новик А. В., Карицкий А. П., Кулева С. А., Нехаева Т. Л., Данилова А. Б. и др. Иммунотерапия рака: современное состояние проблемы. Аллергология и иммунология. 2015; 16 (4): 354

14. Славянская Т. А., Сальникова С. В. Иммунологические критерии и маркеры для диагностики и прогнозирования рака мочевого пузыря. International Journal on Immunorehabilitation. 2009; 11 (1): 24.

15. Slavyanskaya TA, Salnikova SV. Immunologic criteria and markers for diagnostics and prognosis of urinary bladder cancer. Int $J$ Immunoreh. 2009; 11 (2): 180.

16. Uhlen M, Zhang C, Lee S, Sjöstedt E, Fagerberg L, Bidkhori G, et al. A pathology atlas of the human cancer transcriptome. Science. 2017: 357 (6352). DOI: 10.1126/science.aan2507.

17. Свитич О. А., Филина А. Б., Ганковская Л. В., Зверев В. В. Роль факторов врожденного иммунитета в процессе опухолеобразования. Медицинская иммунология. 2018; 20 (2): 151-62.

18. Хаитов Р. М., Кадагидзе 3. Г. Иммунитет и рак. М.: ГеотарМедиа, 2018. 256 с.

19. Crowe NY, Coquet JM, Berzins SP, et al. Differential Antitumor Immunity Mediated by NKT Cells Subsets in Vivo. J Exp Med. 2005; (202): 1279-88.

20. Brandes M, Willimann K, Moser B. Professional Antigenpresentation Function by Human Gammadelta T Cells. Science. 2005; (309): 264-8.

21. Mellman I, Coukos G, Dranoff G. Cancer immunotherapy comes of age. Nature. 2011; 480 (7378): 480-9. 
22. Shevach EM. CD4+, CD25+ suppressor T-cells: More Questions than Answers. Nat Rev Immunol. 2002; (2): 389-400.

23. Lima L, Oliveira D, Tavares A, Amaro T, Cruz R, Oliveira MJ, et al. The predominance of M2-polarized macrophages in the stroma of lowhypoxic bladder tumors is associated with BCG immunotherapy failure. Urol Oncol. 2014; (32): 449-57.

24. LaRue H, Ayari C, Bergeron A, Fradet Y. Toll-like receptors in urothelial cells-targets for cancer immunotherapy. Nat Rev Urol. 2013; 10 (9): 537-45.

25. Diesendruck $\mathrm{Y}$, Benhar I. Novel immune check point inhibiting antibodies in cancer therapy-opportunities and challenges. Drug Resist Updat. 2017; (30): 39-47.

26. Kavecansky J, Pavlick AC. Beyond Checkpoint Inhibitors: pii: E189The Next Generation of Immunotherapy in Oncology. AJHO 2017; 13 (2): 9-20.

27. Ata R, Antonescu CN. Integrins and cell metabolism: an intimate relationship impacting cancer. Int J Mol Sci. 2017; 18 (1). DOl: 10.3390/ijms 18010189 .

28. Hadley GA, Higgins JM. Integrin $\alpha E \beta 7$ : molecular features and functional significance in the immune system. Adv Exp Med Biol. 2014; (819): 97-110.

29. Takimoto C. Forty Seven, Inc. Trial of Hu5F9-G4 in combination with cetuximab in patients with solid tumors and advanced colorectal cancer (NCT02953782). Accessed February 8, 2017 Clinicaltrials. gov website. Available from: https://clinicaltrials.gov/ ct2/show/NCT02953782? ter-m=NCT02953782 \& rank=1.

30. Desgrosellier JS, Cheresh DA. Integrins in cancer: biological implications and therapeutic opportunities. Nat Rev Cancer. 2010; 10 (1): 9-22.

31. Hersey P, Sosman J, O'Day S, et al. Etaracizumab Melanoma Study Group. A randomized phase 2 study of etaracizumab, a monoclonal antibody against integrin alpha(v)beta(3), + or dacarbazine in patients with stage IV metastatic melanoma. Cancer. 2010; 116 (6): 1526-34.

32. Sturgill ER, Redmond WL. TNFR Agonists: A Review of Current Biologics Targeting OX40, 4-1BB, CD27, and GITR. AJHO. 2017; 13 (11): 4-15.

33. Stanley ER, Chitu V. CSF-1 receptor signaling in myeloid cells. Cold Spring Harb Perspect. Biol. 2014; (6): 1-21.

34. Desar IM, Jacobs JH, Hulsbergen-vandeKaa CA, et al. Sorafenib reduces the percentage of tumour infiltrating regulatory $T$ cells in renal cell carcinoma patients. Int J Cancer. 2011; 129 (2): 507-12. DOI: 10.1002/ijc.25674.

35. Adotevi O, Pere $\mathrm{H}$, Ravel P, et al. A decrease of regulatory $\mathrm{T}$ cells correlates with overall survival after sunitinib-based antiangiogenic therapy in metastatic renal cancer patients. J Immunother. 2010; 33 (9): 991-8. DOI: 10.1097/CJl.0b013e3181f4c208.

36. Albeituni SH, Ding C, Yan J. Hampering immune suppressors: therapeutic targeting of myeloid-derived suppressor cells in cancer. Cancer J. 2013; 19 (6): 490-501. DOI: 10.1097/ PPO.0000000000000006.

37. Ling $Z Q$, Li $P, G e M H$, et al. Hypermethylation-modulated downregulation of $\mathrm{CDH} 1$ expression contributes to the progression of esophageal cancer. Int J Mol Med. 2011; (27): 625-35.

38. Глушанкова Н. А., Житняк И. Ю., Айолло Д. В., Рубцова С. Н. Роль Е-кадхерина в неопластической эволюции эпителиальных клеток. Успехи молекулярной онкологии. 2014; (1): 12-17.

39. Scognamiglio G, De Chiara A, Di Bonito M, et al. Variability in immunohistochemical detection of programmed death ligand 1 (PD-L1) in cancer tissue types. Int J Mol Sci. 2014; 17 (5): pii E790.

40. Abaza YM, Alemany C. Nanoparticle albumin-bound-paclitaxe in the treatment of metastatic urethral adenocarcinoma: the significance of molecular profiling and targeted therapy. Case Rep Urol. 2014; (2014): 1-3. DOI: 10.1155/2014/489686.

41. Gong J, Chehrazi-Raffle A. Development of PD-1 and PD-L1 inhibitors as a form of cancer immunotherapy: a comprehensive review of registration trials and future considerations. Journal for Immunotherapy of Cancer. 2018; (6): 8.

42. Velez MA, Wu Y, Dubinett SM, Dong Z, Wu S, Garon EB. Lung cancer. In: Butterfield LH, Kaufman HL, Marincola FM, editors. Cancer immunotherapy principles and practice. New York: Demosmedical, 2017; p. 728
43. Bellmunt J, de Wit R, Vaughn DJ, et al. KEYNOTE-045 Investigators. Pembrolizumab as second-line therapy for advanced urothelial carcinoma. N Engl J Med. 2017; 376 (11): 1015-26.

44. Postow MA, Chesney J, Pavlick AC, Robert C, Grossmann K, McDermott $D$, et al. Nivolumab and ipilimumab versus ipilimumab in untreated melanoma. N Engl J Med. 2015; (372): 2006-17.

45. Massard C, Gordon MS, Sharma S, et al. Safety and efficacy of durvalumab (MEDI4736), an anti-programmed cell death ligand-1 immune checkpoint inhibitor, in patients with advanced urothelial bladder cancer. J Clin Oncol. 2016; 34 (26): 3119-25.

46. Segal NH, Logan TF, Hodi FS, et al. Results from an integrated safety analysis of urelumab, an agonist anti-CD137 monoclonal antibody. Clin Cancer Res. 2017; 23 (8): 1929-36.

47. Goding SR, Wilson KA, Xie Y, et al. Restoring immune function of tumor-specific $\mathrm{CD} 4^{+} \mathrm{T}$ cells during recurrence of melanoma. J Immunol. 2013; 190 (9): 4899-909. DOI: 10.4049/jimmunol.1300271.

48. Ohkuri T, Ghosh A, Kosaka A, et al. STING contributes to antiglioma immunity via triggering type I IFN signals in the tumor microenvironment. Cancer Immunol Res. 2014; 2 (12): 1199208. DOI: 10.1158/2326-6066.CIR-14-0099.

49. Lu H, Wagner WM, Gad E, et al. Treatment failure of a TLR- 7 agonist occurs due to self-regulation of acute inflammation and can be overcome by IL10 blockade. J Immunol. 2010; 184 (9): 5360-67. DOI: 10.4049/jimmunol.0902997.

50. Salmon H, Idoyaga J, Rahman A, et al. Expansion and activation of CD103(+) dendritic cell progenitors at the tumor site enhances tumor responses to therapeutic PD-L1 and BRAF inhibition. Immunity. 2016; 44 (4): 924-38. DOI: 10.1016/j. immuni.2016.03.012.

51. De Witte MA, Kierkels GJ, Straetemans T, Britten CM, Kuball J. Orchestrating an immune response against cancer with engineered immune cells expressing aßTCRs, CARs, and innate immune receptors: an immunological and regulatory challenge. Cancer Immunol Immunother. 2015; 64 (7): 893-902. DOI: 10.1007/s00262-015-1710-8.

52. Holzinger A, Barden M, Abken $\mathrm{H}$. The growing world of CAR T cell trials: a systematic review. Cancer Immunol Immunother. 2016; 65 (12): 1433-50.

53. Eriksson E, Milenova I, Wenthe J, et al. Shaping the tumor stroma and sparking immune activation by CD40 and 4-1BB signaling induced by an armed oncolytic virus. Clin Cancer Res. 2017; 23 (19): 5846-57.

54. El-Khoueiry AB, Hamid O, Thompson JA, et al. The relationship of pharmacodynamics (PD) and pharmacokinetics (PK) to clinical outcomes in a phase I study of OX40 agonistic monoclonal antibody (mAb) PF-04518600 (PF-8600). J Clin Oncol. 2016; 35 (suppl; abst 3027).

55. Linch S, Kasiewicz MJ, McNamara M, Hilgart I, Farhad M, Redmond W. Galectin-3 inhibition using novel inhibitor GR-MD-02 improves survival and immune function while reducing tumor vasculature. J Immunother Cancer. 2015; 3 (suppl 2): 306.

56. Redmond WL, Linch SN, Kasiewicz MJ. Combined targeting of co-stimulatory (OX40) and co-inhibitory (CTLA-4) pathways elicits potent effector $T$ cells capable of driving robust antitumor immunity. Cancer Immunol Res. 2014; 2 (2): 142-53. DOI: 10.1158/2326-6066.CIR-13-0031-T.

57. McHugh RS, Whitters MJ, Piccirillo CA, et al. CD4(+)CD25(+) immunoregulatory $T$ cells: gene expression analysis reveals a functional role for the glucocorticoid-induced TNF receptor. Immunity. 2002; 16 (2): 311-23.

58. Tesaro A. Phase I study of TSR-022, an anti-TIM-3 mono-clonal antibody, in patients with advanced solid tumors (NCT02817633). Accessed 2017 February 7; Available from: https://clinicaltrials. gov/ct2/show/NCT02817633?term=NCT02817633\&rank $=1$.

59. Novartis. Safety and efficacy of MBG453 as single agent and in combination with PDR001 in patients with advanced malignancies (NCT02608268). Accessed 2017 February 7; Available from: https:// clinicaltrials.gov/ct2/show/NCT02678338?term=NCT02678338\& rank=1.

60. Cancer Immunotherapy Guidelines. Accessed 2017 March 8. Available from:http://www.sitcancer.org/research/cancer-immunotherapy-guidelines.

61. Славянская Т. А., Сальникова С. В. и др. Противоопухолевые вакцины: потенциальные мишени, современные разработки и 
перспективы использования. Российский иммунологический журнал. 2016; 10 (19), (2-1): 498-500.

62. Melero I, Gaudernack G, Gerritsen W, Huber C, Parmiani G Scholl S, et al. Therapeutic vaccines for cancer: an overview of clinical trials. Nat Rev Clin Oncol. 2014; (11): 509-24.

63. Palucka K, Banchereau J. Cancer immunotherapy via dendritic cells. Nat Rev Cancer. 2012; (12): 265-77.

64. Славянская Т. А., Сальникова С. В. и др. Целенаправленная терапия больных с уротелиальной карциномой. Аллергология и иммунология. 2016; 17 (2): 153.

65. Beatty GL, O'Dwyer PJ, Clark J, et al. First-in-human phase I study of the oral inhibitor of indoleamine 2,3-dioxygenase-1epacadostat (INCB024360) in patients with advanced solid malignancies [ePub ahead of print]. Clin Cancer Res. 2017; pii: clincanres.2272.2016. DOI: 10.1158/1078-0432.CCR-16-2272.

66. Peethambaram PP, Melisko ME, Rinn KJ, Alberts SR, Provost NM Jones LA, et al. A phase I trial of immunotherapy with lapuleucel-T (APC8024) in patients with refractory metastatic tumors that express HER-2/neu. Clin Cancer Res. 2009; (15): 5937-44.

67. Lowenfeld L, Mick R, Datta J, et al. Dendritic cell vaccination enhances immune responses and induces regression of HER2pos DCIS independent of route: results of randomized selection design trial [ePub ahead of print]. Clin Cancer Res. 2016; pii: clincanres: 1924; 2016.

68. Lesterhuis WJ, Schreibelt G, Scharenborg NM, et al. Wild-type and modified gp100 peptide-pulsed dendritic cell vaccination of advanced melanoma patients can lead to long-term clinica responses independent of the peptide used. Cancer Immunol Immunother. 2011; 60 (2): 249-60.

69. Чкадуа Г. З., Заботина Т. Н., Буркова А. А., Тамаева З. Э., Огородникова Е. В., Жорданиа К. И. Адаптирование методики культивирования дендритных клеток человека из моноцитов периферической крови для клинического применения. Российский биотерапевтический журнал. 2002; (3): 56-62.

70. Sasada T, Suekane S. Variation of tumor-infiltrating lymphocytes in human cancers: controversy on clinical significance. Immunotherapy. 2011; 3 (10): 1235-51.

71. Eloy JO, Petrilli R, Trevizan LNF, Chorilli M. Immunoliposomes: a review on functionalization strategies and targets for drug delivery. Colloids Surf B: Biointerfaces. 2017; (159): 454-67.

72. Bilensoy E, Sarisozen C, Esendagli G, Dogan AL, Aktaş Y, Sen M, et al. Intravesical cationic nanoparticles of chitosan and polycaprolactone for the delivery of Mitomycin $C$ to bladder tumors. Int J Pharm. 2009; (371): 170-6.

73. Kosmides AK, Sidhom JW, Fraser A, Bessell CA, Schneck JP. Dual targeting nanoparticle stimulates the immune system to inhibit tumor growth. ACS Nano. 2017; 11 (6): 5417-29.

74. Zhang Q, Neoh KG, Xu L, Lu S, Kang ET, Mahendran R, et al. Functionalized mesoporous silica nanoparticles with mucoadhesive and sustained drug release properties for potential bladder cancer therapy. Langmuir. 2014; (30): 6151-61.

75. Sudha T, Bharali DJ, Yalcin M, Darwish NH, Coskun MD, Keating KA, et al. Targeted delivery of cisplatin to tumor xenografts via the nanoparticle component of nano-diamino-tetrac. Nanomedicine. 2017; 12 (3): 195-205

76. McKiernan JM, Barlow LJ, Laudano MA, Mann MJ, Petrylak DP, Benson MC. A phase I trial of intravesical nanoparticle albuminbound paclitaxel in the treatment of bacillus Calmette-Guérin refractory nonmuscle invasive bladder cancer. J Urol. 2011; (186): 448-51.

77. Barrow AD, Edeling MA, Trifonov V, Luo J, Goyal P, Bohl B, et al. Natural killer cells control tumor growth by sensing a growth factor. Cell. 2018; 172 (3): 534-48.

\section{References}

1. Kudryavceva IV, Slavyanskaya TA, Trunov AN, Trunova LA. Urovni autoantitel k jadernym DNK, laktoferrina i nekotorye immunologicheskie pokazateli u bol'nyh revmatoidnym artritom. Bjulleten' Sibirskogo otdelenija Rossijskoj akademii medicinskih nauk. 1999; 19 (3-4): 66-8.

2. Smipnova TA, Ponomapeva EP, Hanfepjan PA, Kolesnikov W. Opyt primenenija ronkolejkina pri terapii jazvennoj bolezni zheludka, associirovannoj s Helicobacter Pylori, v ambulatornyh uslovijah. Terapevticheskij arhiv. 2009; 81 (2): 30-5.

3. Slavyanskaya TA, Sepiashvili RI, Vishnyakov MN, Chihladze MV Immunologicheskij monitoring bol'nyh hronicheskim bronhitom $\checkmark$ dinamike vosstanovitel'noj immunoreabilitacii. Internationa Journal on Immunorehabilitation. 1999; (11): 70.

4. Slavyanskaya TA, Avdonkina NA, Salnikova SV. Optimizacija uslovij poluchenija zhiznesposobnoj pervichnoj kul'tury kletok urotelial'noj karcinomy. Allergologija i immunologija. 2016; 17 (3): 176-9.

5. Burger M, Thiounn N, Denzinger S, Kondas J, Benoit G, Chapado MS, et al. The application of adjuvant autologous antravesical macrophage cell therapy vs. BCG in non-muscle invasive bladder cancer: a multicenter, randomized trial. J Transl Med. 2010; (8): 54.

6. Camisaschi C, Vallacchi V, Vergani E, et al. Targeting immune regulatory networks to counteract immune suppression in cancer. Vaccines (Basel). 2016; 4 (4): pii: E38.

7. Dominguez G, Condamine TC, Mony S, et al. Selective targeting of myeloid-derived suppressor cells in cancer patients using DS8273a, an agonistic TRAIL-R2 antibody. Clin Cancer Res. 2016; 23 (12): 2942-50.

8. Sharma P, Retz M, Seifker-Radtke A, et al. Nivolumab in metastatic urothelial carcinoma after platinum therapy (Check-Mate 275): a multicentre, single-arm, phase 2 trial. Lancet Oncol. 2017; 18 (3): 312-22.

9. Larkin J, Chiarion-Sileni V, Gonzalez R, Grob JJ, Cowey CL, Lao CD, et al. Combined nivolumab and ipilimumab or monotherapy in untreated melanoma. N Engl J Med 2015; (373): 23-34.

10. Sepiashvili RI, Beljaev AM. Immunoterapija raka: problemy i perspektivy. Allergologija i immunologija. 2015; 16 (4): 354-7.
11. Salnikova SV, Slavyanskaya TA, i dr. Innovacionnye tehnologii v lechenii raka mochevogo puzyrja. Allergologija i immunologija. 2016; 17 (1): 21-6

12. Salnikova SV, Slavyanskaya TA, i dr. Sovremennye podhody i dostizhenija v lechenii raka mochevogo puzyrja. Allergologija i immunologija. 2016; 17 (1): 50-1.

13. Baldueva IA, Novik AV, Karickij AP, Kuleva SA, Nehaeva TL, Danilova $A B$, i dr. Immunoterapija raka: sovremennoe sostojanie problemy. Allergologija i immunologija. 2015; 16 (4): 354.

14. Slavyanskaya TA, Salnikova SV. Immunologicheskie kriterii markery dlja diagnostiki i prognozirovanija raka mochevogo puzyrja. International Journal on Immunorehabilitation. 2009; $11(1): 24$.

15. Slavyanskaya TA, Salnikova SV. Immunologic criteria and markers for diagnostics and prognosis of urinary bladder cancer. Int $J$ Immunoreh. 2009; 11 (2): 180.

16. Uhlen M, Zhang C, Lee S, Sjöstedt E, Fagerberg L, Bidkhori G, et al. A pathology atlas of the human cancer transcriptome. Science. 2017; 357 (6352). DOI: 10.1126/science.aan2507.

17. Svitich OA, Filina AB, Gankovskaja LV, Zverev W. Rol' faktorov vrozhdennogo immuniteta $\vee$ processe opuholeobrazovanija. Medicinskaja immunologija. 2018; 20 (2): 151-62.

18. Haitov RM, Kadagidze ZG. Immunitet i rak. M.: Geotar-Media, 2018. 256 c.

19. Crowe NY, Coquet JM, Berzins SP, et al. Differential Antitumor Immunity Mediated by NKT Cells Subsets in Vivo. J Exp Med. 2005; (202): 1279-88.

20. Brandes M, Willimann K, Moser B. Professional Antigenpresentation Function by Human Gammadelta T Cells. Science. 2005; (309): 264-8.

21. Mellman I, Coukos G, Dranoff G. Cancer immunotherapy comes of age. Nature. 2011; 480 (7378): 480-9.

22. Shevach EM. CD4+ ${ }^{+}, \mathrm{CD}_{2} 5^{+}$suppressor T-cells: More Questions than Answers. Nat Rev Immunol. 2002; (2): 389-400.

23. Lima L, Oliveira D, Tavares A, Amaro T, Cruz R, Oliveira MJ, et al. The 
predominance of M2-polarized macrophages in the stroma of lowhypoxic bladder tumors is associated with BCG immunotherapy failure. Urol Oncol. 2014; (32): 449-57.

24. LaRue H, Ayari C, Bergeron A, Fradet Y. Toll-like receptors in urothelial cells-targets for cancer immunotherapy. Nat Rev Urol. 2013; 10 (9): 537-45.

25. Diesendruck $Y$, Benhar I. Novel immune check point inhibiting antibodies in cancer therapy-opportunities and challenges. Drug Resist Updat. 2017; (30): 39-47.

26. Kavecansky J, Pavlick AC. Beyond Checkpoint Inhibitors: pii E189The Next Generation of Immunotherapy in Oncology. AJHO. 2017; 13 (2): 9-20.

27. Ata R, Antonescu CN. Integrins and cell metabolism: an intimate relationship impacting cancer. Int J Mol Sci. 2017; 18 (1). DOI: 10.3390/ijms18010189.

28. Hadley GA, Higgins JM. Integrin $\alpha E \beta 7$ : molecular features and functional significance in the immune system. Adv Exp Med Biol. 2014; (819): 97-110.

29. Takimoto C. Forty Seven, Inc. Trial of Hu5F9-G4 in combination with cetuximab in patients with solid tumors and advanced colorectal cancer (NCT02953782). Accessed February 8, 2017; Clinicaltrials. gov website. Available from: https://clinicaltrials.gov/ ct2/show/NCT02953782? ter-m=NCT02953782 \& rank=1.

30. Desgrosellier JS, Cheresh DA. Integrins in cancer: biological implications and therapeutic opportunities. Nat Rev Cancer. 2010; 10 (1): 9-22.

31. Hersey P, Sosman J, O'Day S, et al. Etaracizumab Melanoma Study Group. A randomized phase 2 study of etaracizumab, a monoclonal antibody against integrin alpha(v)beta(3), + or dacarbazine in patients with stage IV metastatic melanoma Cancer. 2010; 116 (6): 1526-34

32. Sturgill ER, Redmond WL. TNFR Agonists: A Review of Current Biologics Targeting OX40, 4-1BB, CD27, and GITR. AJHO. 2017; 13 (11): 4-15.

33. Stanley ER, Chitu V. CSF-1 receptor signaling in myeloid cells. Cold Spring Harb Perspect Biol. 2014; (6): 1-21.

34. Desar IM, Jacobs JH, Hulsbergen-vandeKaa CA, et al. Sorafenib reduces the percentage of tumour infiltrating regulatory $T$ cells in renal cell carcinoma patients. Int J Cancer. 2011; 129 (2): 507-12. DOI: 10.1002/ijc.25674.

35. Adotevi $\mathrm{O}$, Pere $\mathrm{H}$, Ravel $\mathrm{P}$, et al. A decrease of regulatory $\mathrm{T}$ cells correlates with overall survival after sunitinib-based antiangiogenic therapy in metastatic renal cancer patients. J Immunother. 2010; 33 (9): 991-8. DOI: 10.1097/CJl.0b013e3181f4c208.

36. Albeituni $\mathrm{SH}$, Ding $\mathrm{C}$, Yan J. Hampering immune suppressors: therapeutic targeting of myeloid-derived suppressor cells in cancer. Cancer J. 2013; 19 (6): 490-501. DOI: 10.1097/ PPO.0000000000000006.

37. Ling $Z Q$, Li $P, G e M H$, et al. Hypermethylation-modulated downregulation of $\mathrm{CDH} 1$ expression contributes to the progression of esophageal cancer. Int J Mol Med. 2011; (27): 625-35

38. Glushankova NA, Zhitnjak IYu, Ajollo DV, Rubcova SN. Rol' E-kadherina $v$ neoplasticheskoj jevoljucii jepitelial'nyh kletok. Uspehi molekuljarnoj onkologii. 2014; (1): 12-17.

39. Scognamiglio G, De Chiara A, Di Bonito $M$, et al. Variability in immunohistochemical detection of programmed death ligand 1 (PD-L1) in cancer tissue types. Int J Mol Sci. 2014; 17 (5): pii E790.

40. Abaza YM, Alemany C. Nanoparticle albumin-bound-paclitaxel in the treatment of metastatic urethral adenocarcinoma: the significance of molecular profiling and targeted therapy. Case Rep Urol. 2014; (2014): 1-3. DOI: 10.1155/2014/489686.

41. Gong J, Chehrazi-Raffle A. Development of PD-1 and PD-L1 inhibitors as a form of cancer immunotherapy: a comprehensive review of registration trials and future considerations. Journal for Immunotherapy of Cancer. 2018; (6): 8.

42. Velez MA, Wu Y, Dubinett SM, Dong Z, Wu S, Garon EB. Lung cancer. In: Butterfield LH, Kaufman HL, Marincola FM, editors. Cancer immunotherapy principles and practice. New York: Demosmedical, 2017; p. 728.

43. Bellmunt $\mathrm{J}$, de Wit $\mathrm{R}$, Vaughn DJ, et al. KEYNOTE-045 Investigators. Pembrolizumab as second-line therapy for advanced urothelial carcinoma. N Engl J Med. 2017; 376 (11): 1015-26.

44. Postow MA, Chesney J, Pavlick AC, Robert C, Grossmann K,
McDermott D, et al. Nivolumab and ipilimumab versus ipilimumab in untreated melanoma. N Engl J Med. 2015; (372): 2006-17.

45. Massard C, Gordon MS, Sharma S, et al. Safety and efficacy of durvalumab (MEDI4736), an anti-programmed cell death ligand-1 immune checkpoint inhibitor, in patients with advanced urothelial bladder cancer. J Clin Oncol. 2016; 34 (26): 3119-25.

46. Segal NH, Logan TF, Hodi FS, et al. Results from an integrated safety analysis of urelumab, an agonist anti-CD137 monoclonal antibody. Clin Cancer Res. 2017; 23 (8): 1929-36.

47. Goding SR, Wilson KA, Xie Y, et al. Restoring immune function of tumor-specific CD4 ${ }^{+} \mathrm{T}$ cells during recurrence of melanoma. J Immunol. 2013; 190 (9): 4899-909. DOI: 10.4049/jimmunol.1300271.

48. Ohkuri T, Ghosh A, Kosaka A, et al. STING contributes to antiglioma immunity via triggering type I IFN signals in the tumor microenvironment. Cancer Immunol Res. 2014; 2 (12): 1199208. DOI: 10.1158/2326-6066.CIR-14-0099.

49. Lu H, Wagner WM, Gad E, et al. Treatment failure of a TLR- 7 agonist occurs due to self-regulation of acute inflammation and can be overcome by IL10 blockade. J Immunol. 2010; 184 (9): 5360-67. DOI: 10.4049/jimmunol.0902997.

50. Salmon H, Idoyaga J, Rahman A, et al. Expansion and activation of CD103(+) dendritic cell progenitors at the tumor site enhances tumor responses to therapeutic PD-L1 and BRAF inhibition. Immunity. 2016; 44 (4): 924-38. DOI: 10.1016/j.immuni.2016.03.012.

51. De Witte MA, Kierkels GJ, Straetemans T, Britten CM, Kuball J. Orchestrating an immune response against cancer with engineered immune cells expressing aßTCRs, CARs, and innate immune receptors: an immunological and regulatory challenge. Cancer Immunol Immunother. 2015; 64 (7): 893-902. DOI: 10.1007/ s00262-015-1710-8.

52. Holzinger A, Barden M, Abken $\mathrm{H}$. The growing world of CAR T cell trials: a systematic review. Cancer Immunol Immunother. 2016; 65 (12): 1433-50.

53. Eriksson E, Milenova I, Wenthe J, et al. Shaping the tumor stroma and sparking immune activation by CD40 and 4-1BB signaling induced by an armed oncolytic virus. Clin Cancer Res. 2017; 23 (19): 5846-57.

54. El-Khoueiry AB, Hamid O, Thompson JA, et al. The relationship of pharmacodynamics (PD) and pharmacokinetics (PK) to clinical outcomes in a phase I study of OX40 agonistic monoclonal antibody (mAb) PF-04518600 (PF-8600). J Clin Oncol. 2016; 35 (suppl; abst 3027).

55. Linch S, Kasiewicz MJ, McNamara M, Hilgart I, Farhad M, Redmond W. Galectin-3 inhibition using novel inhibitor GR-MD-02 improves survival and immune function while reducing tumor vasculature. J Immunother Cancer. 2015; 3 (suppl 2): 306.

56. Redmond WL, Linch SN, Kasiewicz MJ. Combined targeting of co-stimulatory (OX40) and co-inhibitory (CTLA-4) pathways elicits potent effector $T$ cells capable of driving robust antitumor immunity. Cancer Immunol Res. 2014; 2 (2): 142-53. DOI: 10.1158/2326-6066.CIR-13-0031-T.

57. McHugh RS, Whitters MJ, Piccirillo CA, et al. CD4(+)CD25(+) immunoregulatory $T$ cells: gene expression analysis reveals a functional role for the glucocorticoid-induced TNF receptor. Immunity. 2002; 16 (2): 311-23.

58. Tesaro A. Rhase I study of TSR-022, an anti-TIM-3 mono- clonal antibody, in patients with advanced solid tumors (NCT02817633). Accessed 2017 February 7; Available from: https://clinicaltrials. gov/ct2/show/NCT02817633?term=NCT02817633\&rank $=1$.

59. Novartis. Safety and efficacy of MBG453 as single agent and in combination with PDR001 in patients with advanced malignancies (NCT02608268). Accessed 2017 February 7; Available from: https:// clinicaltrials.gov/ct2/show/NCT02678338?term=NCT02678338\& rank=1.

60. Cancer Immunotherapy Guidelines. Accessed 2017 March 8. Available from: http://www.sitcancer.org/research/cancer-immunotherapyguidelines.

61. Slavyanskaya TA, Salnikova SV, i dr. Protivoopuholevye vakciny: potencial'nye misheni, sovremennye razrabotki i perspektivy ispol'zovanija. Rossijskij immunologicheskij zhurnal. 2016; 10 (19), (2-1): 498-500

62. Melero I, Gaudernack G, Gerritsen W, Huber C, Parmiani G, 
Scholl S, et al. Therapeutic vaccines for cancer: an overview of clinical trials. Nat Rev Clin Oncol. 2014; (11): 509-24.

63. Palucka K, Banchereau J. Cancer immunotherapy via dendritic cells. Nat Rev Cancer. 2012; (12): 265-77.

64. Slavyanskaya TA, Salnikova SV, i dr. Celenapravlennaja terapija bol'nyh s urotelial'noj karcinomoj. Allergologija i immunologija. 2016; 17 (2): 153.

65. Beatty GL, O'Dwyer PJ, Clark J, et al. First-in-human phase I study of the oral inhibitor of indoleamine 2,3-dioxygenase-1epacadostat (INCB024360) in patients with advanced solid malignancies [ePub ahead of print]. Clin Cancer Res. 2017; pii: clincanres.2272.2016. DOI: 10.1158/1078-0432.CCR-16-2272.

66. Peethambaram PP, Melisko ME, Rinn KJ, Alberts SR, Provost NM Jones LA, et al. A phase I trial of immunotherapy with lapuleucel-T (APC8024) in patients with refractory metastatic tumors that express HER-2/neu. Clin Cancer Res. 2009; (15): 5937-44.

67. Lowenfeld L, Mick R, Datta J, et al. Dendritic cell vaccination enhances immune responses and induces regression of HER2pos DCIS independent of route: results of randomized selection design trial [ePub ahead of print]. Clin Cancer Res. 2016; pii: clincanres: 1924; 2016.

68. Lesterhuis WJ, Schreibelt G, Scharenborg NM, et al. Wild-type and modified gp100 peptide-pulsed dendritic cell vaccination of advanced melanoma patients can lead to long-term clinical responses independent of the peptide used. Cancer Immuno Immunother. 2011; 60 (2): 249-60.

69. Chkadua GZ, Zabotina TN, Burkova AA, Tamaeva ZYe, Ogorodnikova EV, Zhordania KI. Adaptirovanie metodik kul'tivirovanija dendritnyh kletok cheloveka iz monocitov perifericheskoj krovi dlja klinicheskogo primenenija. Rossijskij bioterapevticheskij zhurnal. 2002; (3): 56-62.
70. Sasada T, Suekane S. Variation of tumor-infiltrating lymphocytes in human cancers: controversy on clinical significance. Immunotherapy. 2011; 3 (10): 1235-51.

71. Eloy JO, Petrilli R, Trevizan LNF, Chorilli M. Immunoliposomes: a review on functionalization strategies and targets for drug delivery. Colloids Surf B: Biointerfaces. 2017; (159): 454-67.

72. Bilensoy E, Sarisozen C, Esendagli G, Dogan AL, Aktaş Y, Sen M, et al. Intravesical cationic nanoparticles of chitosan and polycaprolactone for the delivery of Mitomycin C to bladder tumors. Int J Pharm. 2009; (371): 170-6.

73. Kosmides AK, Sidhom JW, Fraser A, Bessell CA, Schneck JP. Dual targeting nanoparticle stimulates the immune system to inhibit tumor growth. ACS Nano. 2017; 11 (6): 5417-29.

74. Zhang Q, Neoh KG, Xu L, Lu S, Kang ET, Mahendran R, et al. Functionalized mesoporous silica nanoparticles with mucoadhesive and sustained drug release properties for potential bladder cancer therapy. Langmuir. 2014; (30): 6151-61.

75. Sudha T, Bharali DJ, Yalcin M, Darwish NH, Coskun MD, Keating KA, et al. Targeted delivery of cisplatin to tumor xenografts via the nanoparticle component of nano-diamino-tetrac. Nanomedicine. 2017; 12 (3): 195-205

76. McKiernan JM, Barlow LJ, Laudano MA, Mann MJ, Petrylak DP, Benson MC. A phase I trial of intravesical nanoparticle albuminbound paclitaxel in the treatment of bacillus Calmette-Guérin refractory nonmuscle invasive bladder cancer. J Urol. 2011; (186): 448-51.

77. Barrow AD, Edeling MA, Trifonov V, Luo J, Goyal P, Bohl B, et al. Natural killer cells control tumor growth by sensing a growth factor. Cell. 2018; 172 (3): 534-48. 